Corresponding author: Percy Alfonso Delgado Rojas National University Federico Villarreal, Lima, Peru pdelgadorojas20@gmail.com

Editor: Dr Altair A. Del Bel Cury

Received: October 14, 2020

Accepted: May 12, 2021

\section{Relationship between extrinsic factors and non-carious cervical lesions in patients of the National Hospital "Hipólito Unánue"}

\author{
Percy Alfonso Delgado Rojas ${ }^{1 *}$ iD
}

Non-carious cervical lesions cause destructive dental disorders that actively contribute to the progressive loss of dental structure and the immediate need for dental treatment, due to their multiple symptoms and factors that produce them. Aim: The purpose of the study was to determine the relationship between extrinsic factors and non-carious cervical lesions in patients of the National Hospital Hipólito Unánue. Methods: The research was of a descriptive correlative type. The sample consisted of male and female patients between 18 and 65 years old, who attended the carielogy service of this hospital. For data collection, 2 questionnaires were used to estimate the values of the extrinsic factors that allowed us to obtain the necessary information on the variables to be studied. Spearman's Rho was applied to determine the relationship between the variable's study. Results: According to Spearman's Rho of 0.622 , compared to $p-0.000<0.01$. Between the variables studied; extrinsic factors and noncarious cervical lesions there is a moderate and significant positive correlation. Conclusion: Through this section it was possible to demonstrate the existing relationship between extrinsic variable factors and non-carious cervical lesions, therefore it was concluded that there is a moderate and significant positive correlation in the sample comprised by the patients of the Hospital in mention.

Keywords: Tooth abrasion. Tooth erosion. Tooth wear. Dentin. Dental stress analysis. 


\section{Introduction}

Oral diseases represent a serious health problem of high frequency with which pain, functional impairment and discomfort are produced, so immediate attention is necessary, as well as its effective and rapid diagnosis to achieve an adequate treatment ${ }^{1}$. Indeed, today's lifestyle follows a regular common pattern in most individuals, in such a way that factors, such as the high rate of stress, eating habits and social demands to which humans are constantly subjected have increased the degree and types of non-carious cervical lesions ${ }^{2}$

In this order of ideas, it is possible to say that non-carious cervical lesions are the loss of tooth structure, located at the amelocementall boundary. It comes in various forms that include sensitivity, in some cases, the dental pulp become compromised ${ }^{3}$. Nevertheless, it should be taken into account that on many occasions these ones are not noticed by health professionals, and even less by patients, which is why it is important to have a correct diagnosis and treatment of these lesions. Unlike cavity-affected dentin, non-carious cervical lesions (NCCLs) present a high degree of sclerosis, with partial or complete obliteration of the dentin tubules, preventing the formation of hybrid layer ${ }^{4}$.

In addition, epidemiologically, It is indicated that lesions caused by imperfections and reduction of dental tissue on the incisal and occlusal surfaces, creates a greater sensation of hypersensitivity. This situation occurs if they originate on the cervical surface, loss of esthetics and gingival retraction, as do non-carious dental lesions, whose origin is multifactorial and with different clinical characteristics ${ }^{1,5}$.

However, González García et al. ${ }^{1}$ argue that lesions in the neck of the teeth are seen and most of the time go unnoticed because of chronic symptomatology, except for exceptions. In fact, chronic loss of tooth structure in the neck of the teeth characterize This kind lesions without having a bacterial etiology, but considering that more than one factor causes it. They can be present in different forms, mainly on the vestibular or oral side of the teeth, with or without dentin sensitivity6.

Indeed, patients with non-carious cervical lesions disguise their esthetic discomfort by avoiding the visibility of these lesions due to enamel loss and gingival regression. Although, these lesions have not aroused much interest in researchers or clinicians, they are now common in clinical practice due to the large increase that has made it one of the frequent stomatological conditions ${ }^{7}$.

In this sense, several studies indicate a highly variable prevalence and propose a positive correlation with demographic factors, age and the use of toothpastes with abrasive components, at least in one of the varieties ${ }^{8}$. Regarding the etiology of NCCLs, toothbrushing was historically considered and identified as the main cause, defining it as toothpaste abrasion'. Several factors influence the rate of abrasion, including the toothbrushing technique, brushing force, brushing frequency, bristle stiffness and toothpaste abrasiveness ${ }^{9}$.

Due to the aforementioned fact and because of the increasing number of patients retaining natural teeth at older ages. The widespread availability of preventive oral care information, the large number of oral hygiene products in home, has increased 
considerable interest toward a better understanding of the functions of toothbrush, toothpaste and toothbrushing behaviors in dental use ${ }^{10}$.

In addition, the consumption of alcohol was also correlated with NCCLs, which is explained due to the erosive potential of some of these beverages ${ }^{11}$. A useful concept concerning NCCLs is the abfraction concept, which is defined as lateral forces that create stress in the cervical areas of the teeth and disrupt the enamel microstructure $^{12}$. In this study, the non-carious cervical lesions that will be considered are erosion, abrasion, abfraction and stress corrosion.

It is important to keep in mind that the initial signs that occur in these types of lesions are not taken as important and are associated with other types of more common or morbid pathologies in the oral cavity. Some of them, such as cariogenic disease or gingivitis are deemed a common condition, without realizing that it is much more worrisome, as it can occur indiscriminately in people regardless of sex, but these pathologies increase over the years.

Therefore, this research considers important aspects of oral health at the national level, those that have not been frequently addressed by previous researchers ${ }^{5}$. In this line of thought, this research verified the relationship between extrinsic factors and non-carious cervical lesions in patients of the Hipólito Unánue National Hospital. In addition, the following research hypothesis was devised: there is a link between extrinsic factors and non-carious cervical lesions in patients of the National Hospital Hipólito Unánue.

The types of non-carious cervical lesions can be found individually in a patient or comprehensively in multiple combinations in the same patient. Due to the etiological factors that can produce them, the cervical third of the dental pieces and the sensitivity caused by these lesions are part of the daily consultation for the dentist. This is due to the difficulties in performing basic and necessary actions such as eating, chewing or laughing, all this product of the loss of dental enamel ${ }^{7}$. In other circumstances, these types of lesions can also be associated with professional practices that have failed.

Throughout history, many authors have defined, based on their evidence, the multifactorial and triggering aspects of non-carious cervical lesions, as well as providing alternative solutions or measures for early diagnosis and treatment with the aim of improving the quality of life of people and avoiding esthetic and functional disability. In this study, the classification established by Cuniberti and Rossi ${ }^{2}$ of non-carious cervical lesions is considered in four types: abrasion, erosion, abfraction and stress corrosion, most of them located at the level of the amelocementary junction border (AJB).

The first one Abrasion According to Cuniberti and Rossi ${ }^{2}$, is the pathological wear of the tooth structure caused by abnormal mechanical processes from foreign objects or substances introduced into the mouth. This process occurs when contacting teeth generate the loss of hard tissues by using mechanisms such as polishing, rubbing or scraping. These sorts of injuries are noticed all through dental structures such as lacquer, dentin, and even cementum. Furthermore, they happen because of the poor toothbrushing method, kinds of toothpaste with high rough substances, and related to the use of mouthwashes ${ }^{12}$. It is important to highlight the role played by harmful habits in the appearance of abrasion. Such habits as holding nails or other work instruments between the teeth and lips, as occurs with shoemakers and construction workers. In 
other cases, certain musical instruments such as the harmonica and factors associated with work such as environmental dust in patients who work with abrasive substances such as carborundum dust ${ }^{3}$. The application of incorrect and inadequate periodontal, prosthetic and orthodontic treatment should also be considered in its etiology.

The second one Erosion, considered also by Cuniberti and Rossi ${ }^{3}$, as the loss of the surface structure of the teeth by chemical action in the continuous presence of demineralizing agents, especially acids. This type of lesion does not involve the presence of bacteria. In addition, Ortuño et al. ${ }^{6}$ state that this kind of lesion due to the continuous presence of demineralizing agents, especially acids of non-bacterial origin, act as catalysts by preparing the dental tissue and accelerating the action of mechanical factors such as incorrect brushing or poorly adapted prostheses, thus favoring faster wear. This type of lesion is characterized by being multifactorial since they include chemical and mechanical factors, and the acids produce demineralization of the enamel in early stages.

In the third place, another lesion that can be presented is Abfraction, wedgeshaped. This lesion is distinguished by being rapidly advancing and destructive, which in advanced cases can lead to tooth fracture ${ }^{5}$. Its etiology involves the lateral or eccentric component in the lingual-vestible direction of the occlusal forces. That case results into the concentration of forces in the amelocemental junction border and thus determining the bending of the tooth, which will oppose this force with another, but in the opposite direction, of equal resistance. That situation will cause tension that manifests itself as fatigue in the cervical third causing the aforementioned bending. Likewise, Cuniberti and Rossi ${ }^{2}$ defined it as compression syndrome because the lesion is evidence of a set of signs (loss of tooth structure in the form of a wedge, and fracture and repeated detachment of restorations) and symptoms (dentin hypersensitivity, when the lesion is active).

The Fourth One According to Rodríguez Chala7, is stress corrosion. This lesion is defined as the synergistic interaction of mechanical forces and corrosive reactions, with climatic, environmental or electrochemical factors, which degenerate or destroy a material. For Ruiz Candina ${ }^{8}$. It is the physicochemical degradation resulting from the biodynamics occurring in the oral cavity. This lesion is referred to as flexural stress in an acidic environment and is the reason why the loss of enamel is approximately 10 times greater than in an environment that is not exposed to these substances.

\section{Materials and Methods}

The present investigation is descriptive and correlational, since the variables were described and the degree of between them was measured ${ }^{13}$. In this sense, variables, extrinsic factors such as polishing, rubbing or scraping to mention some and also non-carious cervical lesions were measured, and then the relationship between them was determined.

With regard to the population used for the research, it consisted of patients over 18 years of age who attended the dental surgery service of the dental department of the National Hospital Hipólito Unánue between the months of January and March 2018, which according to the statistical information source consulted would be limited with an average of 252 monthly patient care. The population was a sample of 100 persons between 18 and 65 years of age was randomly drawn. 
The formula used was as follows:

$$
n=\frac{z^{2}(p * q)}{e^{2}+\frac{z^{2}(p * q)}{N}}
$$

Where:

$\mathrm{n}$ : Sample size

z: Desired confidence level

p: Proportion of the population to the desired characteristic (success)

q: Proportion of population without desired characteristic (failure)

e: Level of error willing to commit

N: Population size

The data were obtained through the application of two instruments; the first was a questionnaire own designed by the author, for the estimation of values in relation to extrinsic factors evaluated, structured by 31 items, under the dichotomous scale (yes/ no); which allowed determining the levels of presence of the dimensions of the variable: factors associated with erosion, abrasion, abfraction and stress of the patients studied, detailing these elements in Table 1. It is important to point out that the questionnaire was validated and its reliability was determined, obtaining a Cronbach's alpha coefficient equal to 0.83. Subsequently, the patients who constituted the units of analysis in this research were surveyed through the use of a questionnaire to collect information on extrinsic factors.

Table 1. Operational definition of the variable Extrinsic Factors

\begin{tabular}{|c|c|c|c|}
\hline Dimensions & Indicators & Items & Levels \\
\hline Associated with the Abrasion & Presence / No Presence & From 9 to 16 & \multirow{3}{*}{$\begin{array}{c}\text { Low: } 0 \text { - } 7 \\
\text { Regular: } 8 \text { - } 16 \\
\text { Intermediate: } 17-24 \\
\text { High: } 25-31\end{array}$} \\
\hline Associated with the Abfraction & Presence/ No Presence & From 16 to 23 & \\
\hline Associated with the Corrosion by Stress & Presence/ No Presence & From 24 to 31 & \\
\hline
\end{tabular}

The second was an observation guide, of own design and applied to measure the estimation of values in relation to medically assessed non-carious cervical lesions, structured by 13 items, under the dichotomous scale; which allowed determining the levels of presence of the dimensions of the referred variable: erosion, abrasion, abfraction and stress corrosion of the studied patients, attending the clinical evaluation of the specialists; these elements are detailed in Table 2. It is worth mentioning that the guide was validated and its reliability was determined, obtaining a Cronbach's alpha coefficient equal to 0.80 . In addition, the observation guide was calibrated according to the criteria used by specialists. This was made in order to conduct the respective clinical evaluation of non-carious cervical lesions, and by these criteria, the levels of these lesions were determined. 
Table 2. Operational definition of variable non-carious cervical lesions.

\begin{tabular}{|c|c|c|c|}
\hline Dimensions & Indicators & Items & Levels \\
\hline Erosion & Presence /No Presence & From 1 to 3 & \multirow{4}{*}{$\begin{array}{c}\text { Low: } 0 \text { - } 3 \\
\text { Regular: } 4-7 \\
\text { Intermediate: } 8 \text { - } 10 \\
\text { High: } 11-13\end{array}$} \\
\hline Abrasion & Presence/No Presence & From 4 to 7 & \\
\hline Abfraction & Presence/non-presence & From 8 to 10 & \\
\hline Corrosion by Stress & Presence/No Presence & From 11 to 13 & \\
\hline
\end{tabular}

For the analysis of the data obtained, a descriptive scheme based on percentages was used and to measure the variables, scales were used to determine the levels of presence according to the scores obtained in the instruments applied. In addition, Spearman's Rho coefficient was applied to establish the relationship between the two variables studied. The software used was the Static Package for Social Sciences SPSS Version No 22, the results are presented in tables, under the use of the scales established for the analysis.

\section{Ethical aspects}

All persons who participated in the research were notified of the purpose of the research and were assured of strict confidentiality, anonymity and that the results would be for the exclusive use of the study. Thus, after agreeing to participate, they signed an informed consent form. Moreover, this research study was submitted to and approved by the Institutional Research Ethics Committee of the Hospital Nacional Hipólito Unánue, under the registration code RCEI-54.

\section{Results}

As Figure 1 shows, $80 \%$ of the patients were diagnosed with dental erosion, while $71 \%$ of the patients were diagnosed with dental abfraction, and additionally $57 \%$ presented cases of abrasion and stress corrosion; these rates correspond to the population of 100 evaluated patients who attended the karyography section of the Hospital Nacional Hipólito Unánue.

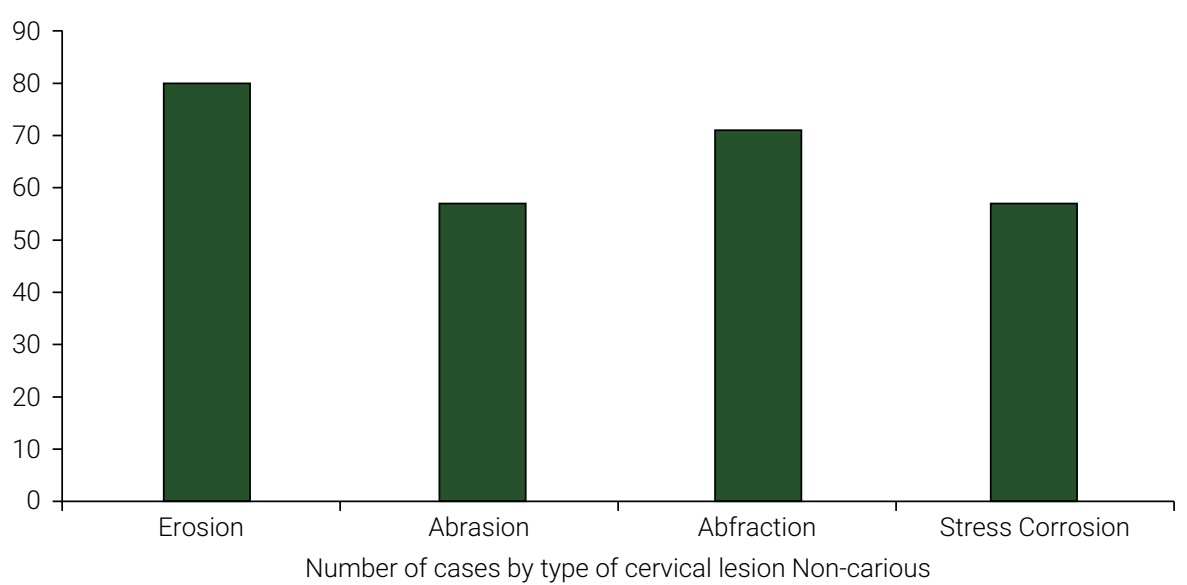

Figure 1. Number of cases by type of non-carious cervical lesion. 
The first dimension of the 4 cervical lesions evaluated was erosion. Figure 2 shows that there is a tendency from an intermediate to a regular level in terms of extrinsic factors and this type of lesion, in this regard $30 \%$ of the patients evaluated presented an intermediate level of extrinsic factors, showing intermediate values associated with dental erosion; On the other hand, $22 \%$ of the patients presented a regular level of extrinsic factors compared to regular levels of presence of erosion, while $12 \%$ presented a low level of extrinsic factors compared to low levels of presence of dental erosion and additionally $10 \%$ of the patients presented high levels of extrinsic factors compared to high levels of presence of dental erosion, the results being evident in relation to the population studied, which were the patients of the National Hospital Hipólito Unánue.

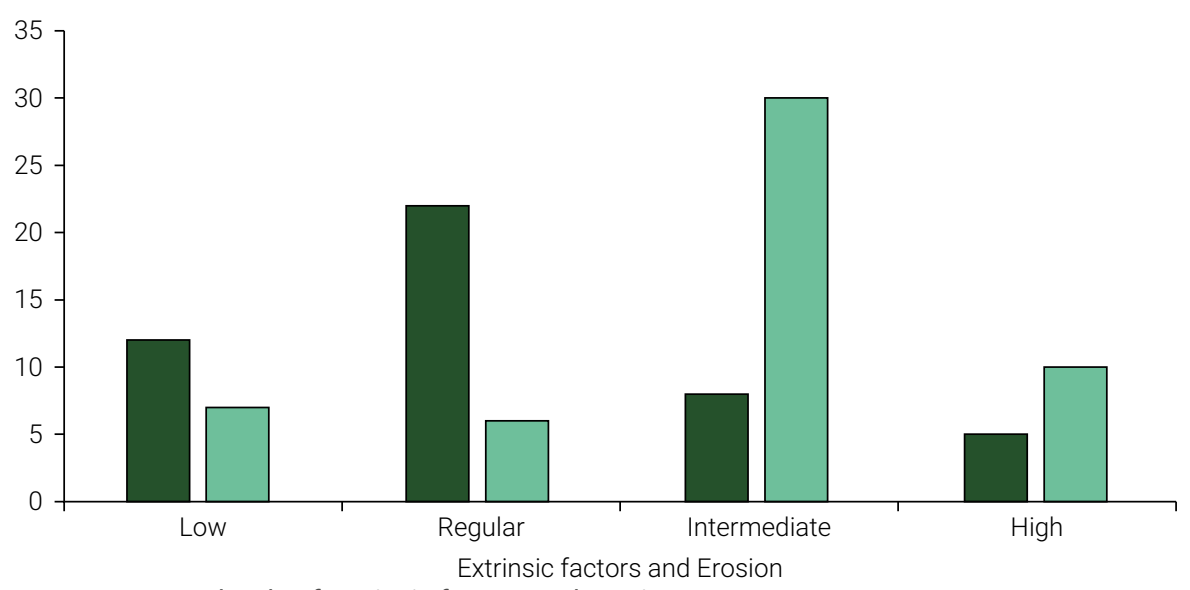

Figure 2. Percentage levels of extrinsic factors and erosion.

The second dimension, of the 4 cervical lesions evaluated, was abrasion, determining that the tendency would be to an intermediate and regular level. In that sense, it has been shown that $27 \%$ of the patients have intermediate levels of extrinsic factors showing intermediate levels of dental abrasion; $24 \%$ had regular levels of extrinsic factors versus regular presence of dental abrasion, $14 \%$ high levels of extrinsic factors versus high levels of dental abrasion, and only $12 \%$ showed low levels of extrinsic factors, showing low presence of dental abrasion as shown in Figure 3.

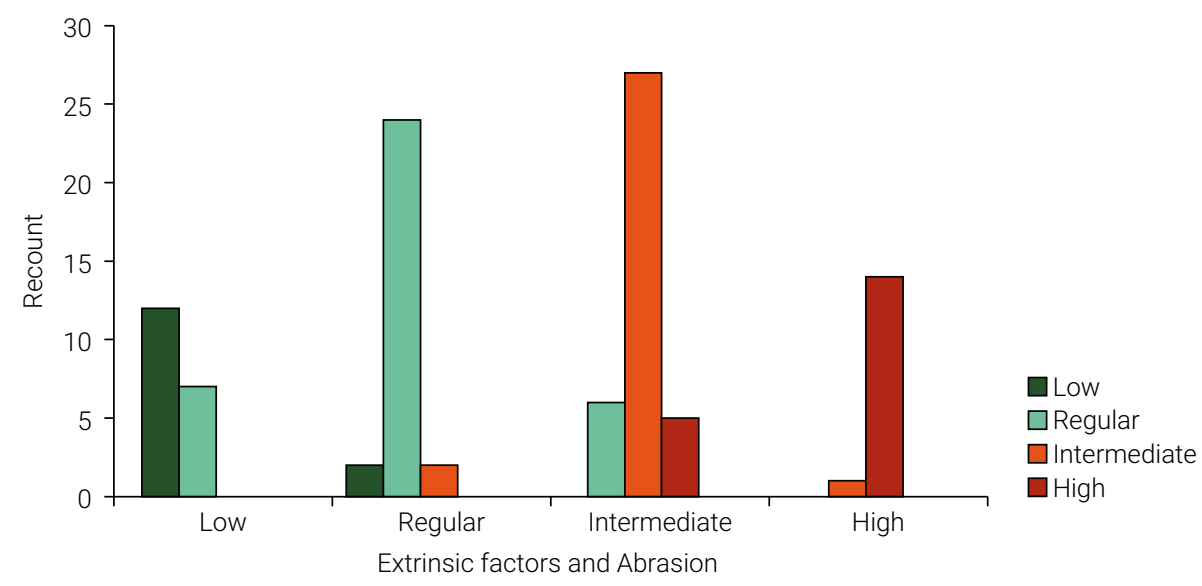

Figure 3. Percentage of extrinsic factors and abrasion levels. 
The third dimension, of the four cervical lesions evaluated, was dental abfraction. Figure 4 shows that there is a tendency from high to intermediate levels in terms of extrinsic factors, in this sense, $22 \%$ of the patients showed intermediate levels of extrinsic factors, showing intermediate levels of the presence of dental abfraction; Likewise, $14 \%$ of the patients presented high levels of extrinsic factors versus a high presence of dental abfraction. Meanwhile, $12 \%$ showed regular levels of extrinsic factors versus regular levels of dental abfraction, and only $13 \%$ of the patients showed low levels of extrinsic factors, showing a low presence of dental abfraction in the patients of the National Hospital Hipólito Unánue.

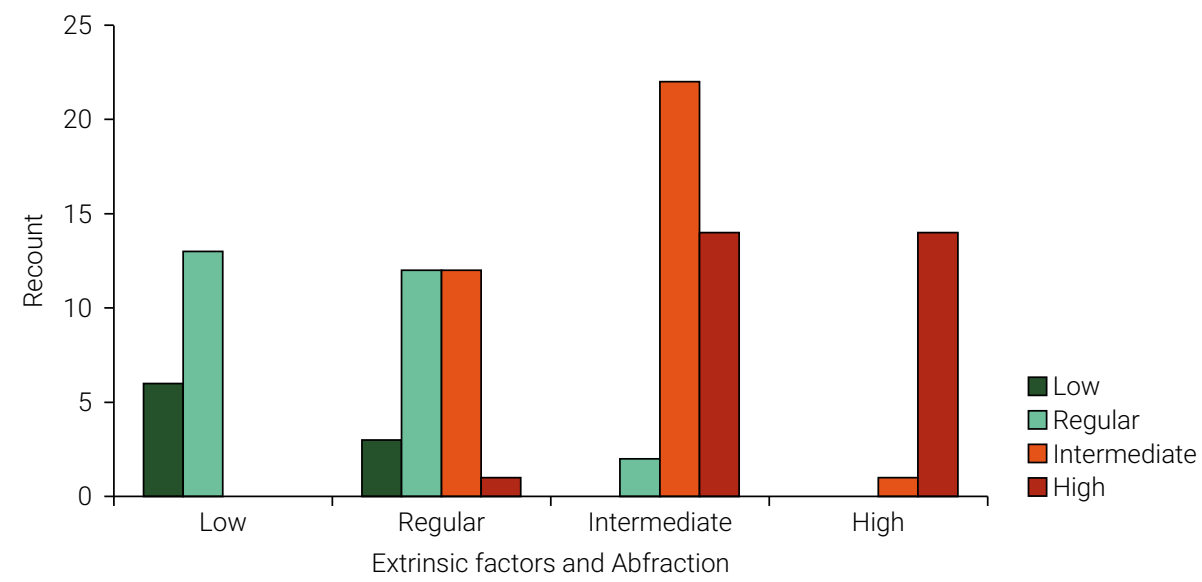

Figure 4. Percentage of extrinsic factors and abfraction.

The fourth and last dimension, of the 4 cervical lesions evaluated, was stress corrosion, showing the existence of an intermediate to low-level trend in extrinsic factors; $25 \%$ of the patients evaluated had intermediate levels of extrinsic factors in the presence of intermediate onset stress corrosion; $15 \%$ had a low level of extrinsic factors in the presence of low stress corrosion; $10 \%$ showed a high level of extrinsic factors expressed in high levels of stress corrosion; and finally, $10 \%$ of patients had regular levels of extrinsic factors when they had regular levels of cervical carious lesions, as it is shown In Figure 5.

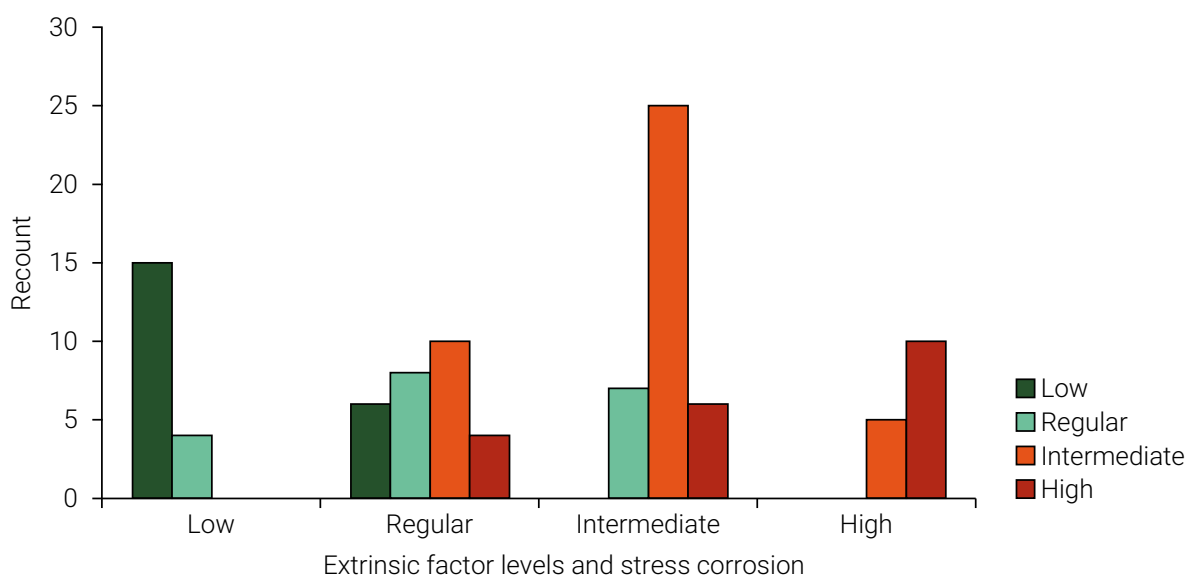

Figure 5. Percentage of extrinsic factor levels and stress corrosion. 


\section{Hypothesis testing}

From the results obtained, shown in Table 3, the statistics are presented in terms of the degree of correlation between the variables determined by Spearman's Rho which is equal to 0.622 indicating that there is a positive, moderate and significant relationship between the variables compared to the degree of statistical significance $p<0.01$, a sufficient condition to reject the null hypothesis ( $\mathrm{Ho}$ ) and accept the alternative hypothesis $(\mathrm{Ha})$ : There is a relationship between extrinsic factors and cervical injuries in patients of the National Hospital Hipólito Unánue.

Table 3. Correlation between extrinsic factors and non-carious cervical lesions

\begin{tabular}{lccc}
\hline RHO of Sperman & & Extrinsic Factors & Non-Carious Cervical Lesions \\
\hline Factors & Correlation coefficient & 1000 & $0.622^{\star *}$ \\
Extrinsic & next. (Bilateral) N & 0.000 \\
\hline N non-carious & Correlation coefficient & $0.622^{\star *}$ & 1000 \\
cervical lesions & next. (Bilateral) N & 0.000 & \\
\hline
\end{tabular}

\section{Discussion}

According to the results obtained, it was possible to determine that there is a positive relationship between extrinsic factors and non-carious cervical lesions, which coincides with the statement of several authors that these factors have a great influence on the development of this type of lesions ${ }^{14}$. Among these extrinsic factors, some foods are mentioned as in contact with acid vapors by inhalation ${ }^{15}$ and even by activities such as swimming ${ }^{16}$. Regarding abrasion, it is evident that the relationship between this non-carious cervical lesion, in terms of extrinsic factors would be between intermediate and regular, which coincides with a study in which this same alteration was evaluated in young people and adults ${ }^{17,18}$.

Alternatively, it was determined that the analysis of the relationship of extrinsic factors with respect to stress corrosion was medium-low, which coincides with the work that shows that although stress corrosion can cause damage, its incidence remains at intermediate levels with respect to external factors such as external acids ${ }^{19}$. However, as the dental cover significantly decreases the stress in the area will increase ${ }^{20}$, especially due to toothbrush misuse, which according to several studies is observed as the main external factor responsible for the appearance of non-carious cervical lesions due to stress ${ }^{21,22}$.

When comparing the results obtained using other studies, the derivations of the research conducted by Busleimán ${ }^{23}$ are confirmed. In that research He concludes that the most frequent lesions found in the cervical third of the dental elements were Non-Cariogenic cervical lesions. Also, He stated that the evaluation of the intermediate factors indicated that the lesions were associated with a low and moderate cariogenic risk, coinciding with the levels reported in this research.

However, in the research conducted by Abarca Pineda ${ }^{24}$, he found that functional habits are the main etiological factors in the appearance of abrasion. Furthermore, in addition, he also found a significant relationship between acidic diets $47.8 \%$ and the 
existence of non-carious cervical lesions (erosion), which indicates that the consumption of acidic foods predisposes to the appearance of such damage, corroborating these results with this study.

In the same line of research, the work of Castillo Guerra ${ }^{25}$ is reaffirmed, who concluded that there is a relationship between the presence of non-carious lesions and a healthy lifestyle. Therefore, a direct correlation was found between variable lifestyle habits and variable non-carious lesions. Likewise, in the research performed by Viera Jácome ${ }^{26}$. The data obtained demonstrate the lack of knowledge of the population about the factors associated with this type of lesion. These results indicate the need for a treatment plan to control hypersensitivity.

It is important to point out that the results obtained by Romero ${ }^{27}$ also confirm the results of this investigation, since it was concluded that a high presence of abfraction lesions and the factors influences their appearance. The level of abfraction was high in patients who suffered emotional stress. This study also reports stress as a determining factor of the referred injuries. In the research conducted by Cerna Bacerra ${ }^{28}$, he reports that there is a high prevalence of non-carious cervical lesions in this study group, the most significant being dental wear, coinciding with the derivations of the research conducted.

In the research performed by Guzmán Zavaleta ${ }^{29}$, among the main results a prevalence of abfractions of $24 \%$ was found, although a greater prevalence of abfractions was observed in patients with higher levels of stress, no statistically significant relationship was found between abfractions and stress levels, these results differ from those of this study, since it was verified that there is a positive relationship between extrinsic factors and non-carious cervical lesions.

Alternatively, the research performed by Segura Escudero ${ }^{30}$ found similar results to this study: among the types of non-carious cervical lesions present in the population, the most frequent were abrasion with a percentage of $60 \%$, followed by abfraction with $48 \%$ and then erosion with $15 \%$. It also showed that there is a relationship between the frequency of abrasion and the time patients take to start brushing.

Likewise, the research performed by Reyes et al. ${ }^{31}$ reported that $83.3 \%$ had dental caries, there was dental wear due to attrition in $43.3 \%$ and wear due to abfraction in $31.7 \%$, concluding that stress has a direct and significant relationship with the presence of non-carious lesions in the population studied; the aspect that is confirmed by similar results in this study.

And in the work carried out by Latorre López ${ }^{32}$. The results showed that $40.7 \%$ of the population studied non-carious lesions. These results reveal some similarities with the results of our investigation., which indicates the existence of a moderate and significant positive correlation between the extrinsic factors of the variable and non-carious cervical lesions in patients at the National Hospital Hipólito Unánue.

Regarding the positive relationship shown between extrinsic factors and dental abrasion, abfraction and stress corrosion, it is recommended that the factors that have a direct impact on the production of these pathologies be consistently and continuously discouraged through educational and demonstration sessions given daily in the waiting rooms by patients and/or students who collaborate daily in the care services. 
There were not significant limitations on this study due to the access of the information, however, like all research, this one required time and dedication for its pertinent development.

In conclusion, there is a moderate and significant positive correlation between the variables Extrinsic Factors and Non-carious Cervical Lesions of the patients of the Hipólito Unánue National Hospital. On the other hand, this study will serve as a basis for the development of future research on this topic, which could be aimed at investigating the risk factors and the correct treatment plan for non-carious cervical lesions. as a scientific contribution of great relevance to future research and projects related to this topic.

\section{Conflict of interest}

The author states that he has no conflict of interest.

\section{References}

1. González García X, Cardentey García J, Martínez Pérez MB. [Non-carious cervical injuries in adolescents in a health care area]. Rev Cienc Med Pinar Rio. 2020;24(2): e4324. Spanish.

2. Cuniberti N, Rossi GH. [Non-carious cervical lesions]. Rev Ateneo Argent. Odontol. 2017;57(2):35-8. Spanish.

3. Cuniberti N, Rossi G. [A different view on non-carious cervical lesions why cervical wedge lesions are not caused by acid erosion]. Rev Oper Dent Biomater. 2017; 6(2): 1-10. Spanish.

4. Loguercio AD, Luque-Martinez IV, Fuentes S, Reis A, Muñoz MA. Effect of dentin roughness on the adhesive performance in non-carious cervical lesions: a double-blind randomized clinical trial. J Dent. 2018 Feb;69:60-9. doi: 10.1016/j.jdent.2017.09.011.

5. Cerón XA, Narváez RF, Madroñero AE, Chávez LS, Tobar AS. [Prevalence of non-carious lesions causing hypersensitivity in patients at the Pasto dental clinic]. Rev Colomb Invest Odontol. 2016;7(19);25-33. Spanish. doi: 10.25063/21457735.234.

6. Ortuño D, Mellado B, Prado S, Vargas JP, Rada G. [Restorations of non-carious cervical lesions: a review protocol systematic for clinical practice]. ARS Med. 2018;43(2):33-41. Spanish. doi: 10.11565/arsmed.v43i2.1073.

7. Rodríguez Chala H, Hernández Pampim Y, González Fernández C. [Non carious cervical lesions in patient of the area of health "Electric",Arroyo Naranjo municipality, 2015]. Rev Cubana Estomatol. 2016;53(4):188-97. Spanish.

8. Ruiz Candina Hj, Herrera Batista AJ, Gamboa Sousa J. [Non-carious dental lesions in patients treated at the Siboney Stomatology Clinic]. Rev Cuba Invest Biomed. 2018;37(2):46-53. Spanish.

9. Sawlani K, Lawson NC, Burgess JO, Lemons JE, Kinderknecht KE, Givan DA, et al. Factors influencing the progression of noncarious cervical lesions: A 5-year prospective clinical evaluation. J Prosthet Dent. 2016 May;115(5):571-7. doi: 10.1016/j.prosdent.2015.10.021.

10. Turssi CP, Kelly AB, Hara AT. Toothbrush bristle configuration and brushing load: Effect on the development of simulated non-carious cervical lesions. J Dent. 2019 Jul;86:75-80. doi: 10.1016/j.jdent.2019.05.026.

11. Yoshizaki KT, Francisconi-Dos-Rios LF, Sobral MA, Aranha AC, Mendes FM, Scaramucci T. Clinical features and factors associated with non-carious cervical lesions and dentin hypersensitivity. J Oral Rehabil. 2017 Feb;44(2):112-8. doi: 10.1111/joor.12469. 
12. Heasman PA, Holliday R, Bryant A, Preshaw PM. Evidence for the occurrence of gingival recession and non-carious cervical lesions as a consequence of traumatic toothbrushing. J Clin Periodontol 2015 Apr;42 Suppl 16:S237-55. doi: 10.1111/jcpe.12330.

13. Hernández R, Fernández C, Baptista P. [Research methodology]. México: GrawHill; 2018. Spanish.

14. Coupal I, Sołtysiak A. Dental erosion in archaeological human remains: A critical review of literature and proposal of a differential diagnosis protocol. Arch Oral Biol. 2017 Dec;84:50-7. doi: 10.1016/j.archoralbio.2017.09.011.

15. Nascimento MM, Dilbone DA, Pereira PN, Duarte WR, Geraldeli S, Delgado AJ. Abfraction lesions: etiology, diagnosis, and treatment options. Clin Cosmet Investig Dent. 2016 May;8:79. doi: $10.2147 /$ CCIDE.S63465.

16. Paryag A, Rafeek R. Dental erosion and medical conditions: an overview of aetiology, diagnosis and management. West Indian Med J. 2014 Sep;63(5):499-502. doi: 10.7727/wimj.2013.140.

17. Jaeggi T, Lussi A. Prevalence, incidence and distribution of erosion. Monogr Oral Sci. 2014;25:55-73. doi: $10.1159 / 000360973$.

18. Teixeira DNR, Zeola LF, Machado AC, Gomes RR, Souza PG, Mendes DC, et al. Relationship between noncarious cervical lesions, cervical dentin hypersensitivity, gingival recession, and associated risk factors: a cross-sectional study. J Dent. 2018 Sep;76:93-7. doi: 10.1016/j.jdent.2018.06.017.

19. Sugita I, Nakashima S, Ikeda A, Burrow MF, Nikaido T, Kubo S, et al. A pilot study to assess the morphology and progression of non-carious cervical lesions. J Dent. 2017 Feb;57:51-6. doi: 10.1016/j.jdent.2016.12.004.

20. Leal NMS, Silva JL, Benigno MIM, Bemerguy EA, Meira JBC, Ballester RY. How mechanical stresses modulate enamel demineralization in non-carious cervical lesions? J Mech Behav Biomed Mater. 2017 Feb;66:50-7. doi: 10.1016/j.jmbbm.2016.11.003.

21. Cerezo-Román J, Anderson B. Deconstructing non-carious cervical lesions on teeth in forensic contexts. In: Schmidt CW, Watson JT, editors. Dental wear in evolutionary and biocultural contexts. London: Elsevier; 2020. p.123-42. doi: 10.1016/B978-0-12-815599-8.00006-X.

22. Matarrita AE, Sotela Truque P. [Case report: treatment of abfraction due to bruxism]. Rev Electron Fac Odontol ULACIT. 2014;7(2):16-32. Spanish.

23. Busleiman Fj. [Evaluation of factors associated with lesions of the cervical third of the dental elements and their relationship with the periodontium] [thesis]. Córdoba: Universidad Nacional de Córdoba; 2015. Spanish.

24. Abarca Pineda JP. [Etiological factors involved in the appearance of non-carious injuries in the university students aged 18-30 National of Loja of the modality of studies presential period may-july 2014] [thesis]. Ecuador: Universidad Nacional de Loja; 2014. Spanish.

25. Castillo Guerra D. [Incidence of non-carious lesions and its relationship with habits that are part of a lifestyle considered healthy in 300 people in the Cumbayá Valley] [thesis]. Ecuador: Universidad San Francisco de Quito; 2011. Spanish.

26. Viera Jácome DG. [Diagnostic study on the incidence of hypersensitivity in patients with non-carious cervical lesions at the San Miguelito Parish Health Center in Santiago de Píllaro County] [thesis]. Píllaro, Ecuador: Universidad Autónoma Regional de los Andes; 2011. Spanish.

27. Romero F. Abfractions: [Abfractions: non-carious cervical in wedge, its relationship with stress]. Acta odontol Venez. 2012; 50(2):1-7. Spanish.

28. Cerna Becerra Al. [Prevalence of tooth enamel alterations in older adults in the "Hogar San José" nursing home in Trujillo, 2016] [thesis]. Trujilio, Perú: Universidad Privada Antenor Orrego; 2016. Spanish.

29. Guzmán Zavaleta VE. [Prevalence of abfractions and its relationship with stress in adult patients served at the Moche Dental Clinic, 2013] [thesis]. Trujilio, Perú: Universidad Nacional de Trujillo; 2013. Spanish. 
30. Segura Escudero JS. [Frequency of non-carious cervical lesions in adult patients between 18 and 60 years of age who attend the clinic of the Faculty of Dentistry of the UNMSM] [thesis]. Perú: Universidad Nacional Mayor de San Marcos; 2013. Spanish.

31. Reyes J, Paz Soldán R, Palian R, Apaza E, García V. [Characteristics of dental wear and occupational stress in technical nursing staff in a psychiatric hospital]. Rev Psiq Salud Mental "Hermilio Valdizán". 2011;12(1):51-62. Spanish.

32. Latorre López EA. [Prevalence of non-carious dental lesions in the community of Santa Rosa annex 22 of Jicamarca - San Juan de Lurigancho in 2009] [thesis]. Lima, Perú: Universidad Inca Garcilaso de la Vega. Facultad de Estomatología; 2011. Spanish. 